\title{
A quantificacạ̃o da qualidade: algumas consideracōes sobre os índices de reprovação escolar no Brasil
}

\section{Natália de Lacerda Gil ${ }^{*}$ (ID)}

\section{Resumo}

Neste artigo, apresento análise acerca das relações, observáveis no caso brasileiro, entre os índices de reprovação escolar e a aferição da qualidade do ensino. A opção foi focalizar as discussões sobre a possibilidade de quantificação da qualidade do ensino desde o século XX. Inicialmente, foi preciso considerar a polissemia do termo qualidade e suas implicações para os processos de quantificação. O exame da documentação permitiu ver que coexistiram, no Brasil, por longo período a naturalização do fraco desempenho escolar dos alunos e críticas aos altos índices de reprovação repudiados como mecanismo de seletividade e exclusão. A articulação entre reprovação escolar e qualidade do ensino é, ainda hoje, perceptível no contexto educacional brasileiro, como se observou pela análise do modo de construção do Índice de Desenvolvimento da Educação Básica (IDEB) que, desde 2007, busca quantificar a qualidade da escola no Brasil. Nesse índice, a aferição dos saberes escolares que os alunos dominam não é condição suficiente para considerar o ensino de qualidade. Tem-se assumido também como necessário garantir um fluxo escolar normalizado, com baixa incidência de reprovação e abandono.

Palavras-chave: educação, estatísticas, IDEB, qualidade da educação, avaliação do ensino.

\footnotetext{
* Universidade Federal do Rio Grande do Sul, Porto Alegre, RS, Brasil.
} 


\section{Introdução}

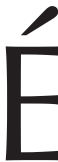

notória, atualmente, a preocupação com a qualidade da educação brasileira. ${ }^{1}$ Os meios de comunicação constantemente divulgam índices e rankings que buscam evidenciar quais seriam as boas escolas e regozijam-se ou espantam-se, também, em noticiar o que sabem (mais frequentemente, o que não sabem) os estudantes da educação básica. ${ }^{2}$ As pesquisas acadêmicas e a ação de organizações privadas sem fins lucrativos também têm dedicado atenção à aferição e/ou ao debate acerca da qualidade do ensino. Se medida pelo direito ao acesso às instituições escolares, a qualidade da educação teria melhorado, mas apresentando, ainda, problemas. É positivo que 99,2\% dos jovens de 6 a 14 anos tenham frequentado a escola em 2017, ${ }^{3}$ mas vale lembrar que isso significa que mais de 211 mil pessoas nessa faixa de idade estavam fora da escola (IBGE, 2018). Em 2017, a média de anos de estudo das pessoas de 25 anos ou mais no Brasil era de 9,1 anos, sendo 10,1 entre pessoas brancas e 8,2 para a população negra. Caso se prefira considerar índices de fluxo escolar, ou seja, estatísticas que indicam se aqueles que ingressam no sistema seguem com regularidade o percurso escolar estabelecido pela legislação, temos, em linhas gerais, o seguinte quadro: entre o 1 o e o $5^{\mathrm{o}}$ ano do Ensino Fundamental ${ }^{4}$ a reprovação, em 2017 , foi de 5,2\%; entre o 6 o e o 9 o ano, passava para 10,1\%; no Ensino Médio, o índice de reprovação escolar

1 Agradeço à Célia Caregnato pela leitura cuidadosa da versão preliminar e pelas valiosas sugestões. Os problemas e incompletudes deste estudo, evidentemente, são de minha inteira responsabilidade.

${ }^{2}$ A título de exemplo, ver "Brasil é segundo país com pior nível de aprendizado, aponta estudo da OCDE", publicado em 10/02/2016 e disponível em https://educacao.uol.com.br/ noticias/agencia-estado/2016/02/10/brasil-e-segundo-pais-com-pior-nivel-de-aprendizadoaponta-estudo-da-ocde.htm e "São Paulo só tem uma escola no top 10 do Enem de 2019", publicado em 27/06/2020 e disponível em https://noticias.uol.com.br/ultimas-noticias/ agencia-estado/2020/06/27/sp-so-tem-uma-escola-no-top-10-do-enem-de-2019.htm.

3 Dados disponíveis em https://agenciadenoticias.ibge.gov.br/agencia-sala-de-imprensa/2013agencia-de-noticias/releases/21253-pnad-continua-2017-numero-de-jovens-que-naoestudam-nem-trabalham-ou-se-qualificam-cresce-5-9-em-um-ano. Acesso em 11/07/2020.

${ }^{4}$ No Brasil, a Educação Básica se divide em três níveis: Educação Infantil, para crianças de 0 a 5 anos; Ensino Fundamental, com duração de 9 anos; e Ensino Médio, com duração de 3 anos. 
atingia 10,8\%. ${ }^{5}$ Como a reprovação é significativa na escola brasileira, temos outro índice ao qual podemos recorrer: o de distorção idade-série. Assim, sabemos que $95,5 \%$ das crianças de 6 a 10 anos frequentavam na idade esperada os anos iniciais do Ensino Fundamental, sem expressiva diferença entre os sexos. No grupo etário dos 11 aos 14 anos, a taxa era de 83,3\% dos homens e $88,0 \%$ das mulheres na idade em que idealmente deveriam frequentar os anos finais do Ensino Fundamental. Para quem está mais preocupado em saber o quanto aprendem os alunos, temos, por exemplo, dados da Prova Brasil. ${ }^{6}$ Nesse caso, uma interpretação possível, a partir da pontuação obtida nas provas padronizadas, é que, entre os alunos do $5^{0}$ ano, 56\% apresentam aprendizado esperado ou além das expectativas em leitura e $44 \%$ em Matemática; entre os do 90 ano, esses percentuais seriam $34 \%$ e $15 \%$ respectivamente. ${ }^{7}$

Em que pese a profusão de números, não é despropositado perguntar: é possível efetivamente quantificar a qualidade? Qual o limite das estatísticas na tarefa de nos permitir conhecer os resultados da educação de um país? E, afinal, o que é qualidade? A questão é espinhosa, como veremos adiante, e quem produz e analisa estatísticas educacionais em geral sabe disso. No entanto, tais números são formulados e apresentados de modo a fazer crer que é sim possível quantificar a qualidade. A perspectiva é animadora e, quase sempre, a animação é suficiente para dar a discussão por encerrada e passarmos de vez à análise dos números. Daí que a dificuldade em quantificar a qualidade passa a ser considerada um problema menor, quando muito passa-se

${ }^{5}$ Dados disponíveis em http://portal.inep.gov.br/artigo/-/asset_publisher/B4AQV9zFY7Bv/ content/inep-divulga-taxas-de-rendimento-escolar-numeros-mostram-tendencia-historicade-melhora/21206.

6 "A Prova Brasil e o Sistema Nacional de Avaliação da Educação Básica (Saeb) são avaliações para diagnóstico, em larga escala, desenvolvidas pelo Instituto Nacional de Estudos e Pesquisas Educacionais Anísio Teixeira (Inep/MEC). Têm o objetivo de avaliar a qualidade do ensino oferecido pelo sistema educacional brasileiro a partir de testes padronizados e questionários socioeconômicos. Nos testes aplicados na quarta e oitava séries (quinto e nono anos) do ensino fundamental, os estudantes respondem a itens (questões) de língua portuguesa, com foco em leitura, e matemática, com foco na resolução de problemas. No questionário socioeconômico, os estudantes fornecem informações sobre fatores de contexto que podem estar associados ao desempenho". Disponível em http://portal.mec. gov.br/prova-brasil.

${ }^{7}$ De acordo com interpretação de QEdu, da Fundação Lemann. Disponível em https://qedu.org.br/ brasil/proficiencia?gclid=EAlalQobChMlovKGq7rF6gIVVQmRCh1BygDbEAAYASAAEgLfCvD_BwE. 
ritualmente pela menção de reconhecimento desse problema metodológico e segue-se à fruição das muitas vantagens que a análise quantitativa parece ter. Da pesquisa científica à ampla divulgação, o problema se deteriora. Porque, quando ganha as manchetes dos jornais, a "qualidade" da educação já se tornou coisa, temos então a reificação da qualidade, e não se volta a discutir do que mesmo se está falando. Os números ganham fluidez e circulam alegremente, de notícia a notícia, permitindo bons insights, mas também quase qualquer tipo de abuso interpretativo.

A reificação é apenas uma das dificuldades com as quais é preciso lidar caso se pretenda pensar com estatísticas. Tais dificuldades não nos permitem advogar pelo abandono das análises quantitativas. Elas são úteis, muito úteis, contribuem indiscutivelmente para a tarefa de conferir inteligibilidade a situações complexas, como é o caso da educação. Talvez o problema seja sucumbir à sedução dos números e o esforço necessário deva ser o de desconfiar da sensação de objetividade que eles nos dão. Não, as estatísticas não são objetivas. São um recurso útil de objetivação - o que é diferente - e comportam riscos, efeitos colaterais, que não podemos desconhecer nem desconsiderar.

Nas últimas três décadas, uma importante literatura crítica sobre a quantificação tem enfatizado que as estatísticas não são uma simples descrição da realidade, são, ao contrário, resultado de processos de objetivação definidos pelas categorias usadas, pela escolha do que se deve mensurar, pelos modos de observar (Hacking, 1990; Rose, 1991, 1999; Porter, 1995; Desrosières, 2000; Popkewitz, 2011, entre outros). Tais processos conferem aos números poder simbólico e, sendo produzidos e usados por e para pessoas, produzem também dispositivos de subjetivação. Bourdieu (1998, p. 117-118) ressalta que

a ordem social deve em parte sua permanência à imposição de esquemas de classificação que, por se ajustarem às classificações objetivas, acabam produzindo uma forma de reconhecimento desta ordem que implica justamente o desconhecimento da arbitrariedade de seus fundamentos: a correspondência entre as divisões objetivas e os esquemas classificatórios, entre as estruturas objetivas e as estruturas mentais, está na raiz de um tipo de adesão originária à ordem estabelecida. 
As estatísticas produzem o que Bourdieu (1998) designou de "efeito de teoria", ou seja, na medida em que buscam prover formas de inteligibilidade do mundo, colaboram na construção das condições de existência daquilo que pretendem descrever.

É no sentido da contribuição a uma análise crítica das estatísticas de educação que, neste artigo, o foco recai sobre os modos de quantificar a qualidade do ensino. Mais especialmente, o que pretendi foi escrutinar como, no caso brasileiro, a reprovação escolar foi tomada como indicador da falta de qualidade da escola brasileira. ${ }^{8}$ Para tanto, recuo a análise ao início do século $X X$, quando temos pela primeira vez a organização sistemática de estatísticas de educação no país. Esse recuo se explica pela intenção de conhecer como os argumentos foram apresentados ao estabelecer-se a escola democrática no Brasil. ${ }^{9}$ Como sugere Bourdieu (2014, p. 103), "o interesse do retorno à gênese é que ele é muito importante porque há debates nos primórdios em que são ditas com todas as letras coisas que, depois, aparecem como revelações provocadoras aos sociólogos".

O texto está organizado em três partes. Na primeira, recorrendo à literatura disponível sobre o tema, embora sem ser exaustiva, procedo à análise sobre a noção de qualidade em educação. A polissemia que caracteriza o termo torna a tarefa difícil, mas, até por isso, tal exame é incontornável se o intuito é quantificar a qualidade. Em seguida, localizo, nos debates educacionais brasileiros, vestígios do que se considerava como elementos articulados em torno da qualidade da escola e sua mensuração. Nesse sentido, importa observar que a quantificação se referia, inicialmente, às características e capacidades do alunado; com o tempo, passou a ser mobilizada, também, para a denúncia da incapacidade de a escola cumprir

\footnotetext{
${ }^{8}$ No senso comum, no entanto, considera-se frequentemente uma alta taxa de reprovação como expressão de qualidade. Mesmo muitos professores seguem pensando desse modo, a despeito de os documentos oficiais e a literatura especializada há mais de um século indicar o contrário. Sobre isso, contudo, não tratarei neste artigo, embora seja uma questão muito importante e ainda pouco estudada.

${ }^{9}$ Nos anos 1930, educadores liberais defenderam a expansão da escola democrática, compreendo-a como instituição que garantiria a igualdade de oportunidade para todos e procederia a uma seleção considerada justa porque apoiada nos talentos inatos dos alunos. Tais defesas tiveram forte influência no modo pelo qual a escola brasileira foi estabelecida na legislação.
} 
seu papel social. Por fim, apresento as concepções que orientam a construção do Índice de Desenvolvimento da Educação Básica (IDEB), criado em 2007, e apresento alguns de seus limites e críticas recorrentes. A intenção não foi proceder a uma análise histórica minuciosa, mas sim perseguir, com rigor metodológico, os argumentos que coexistem, muitas vezes de modo contraditório, nos debates sobre qualidade da educação brasileira ao longo do tempo.

\section{Como quantificar a qualidade em educação?}

Afinal, o que é qualidade? Este é um terreno difícil, cheio de pedras e risco de tropeços. Inicialmente, importa afirmar que qualidade, especialmente da educação, é um conceito polissêmico. Quanto a essa constatação, estão de acordo os muitos autores que se dedicam ao exame da questão. Há vários elementos a levar em conta. Sem pretender estabelecer uma sequência temporal e, menos ainda, qualquer hierarquia, comecemos observando que se trata de um conceito histórico, porque se altera ao longo do tempo articulando-se aos valores, saberes e expectativas compartilhados socialmente em diferentes períodos. É frequente que a menção sugira uma sucessão temporal linear e progressiva, que leva a crer que a variação de sentido do termo qualidade da educação estabeleceria, nas transições históricas, alterações totais de sentido. Ora, como pretendemos argumentar ao longo deste artigo, a análise dos processos históricos nos conduz não à compreensão de uma sequência de sentidos de qualidade que substituiriam seus precedentes, mas sim à percepção da coexistência de sentidos formulados em diferentes temporalidades.

Outro aspecto a ser observado refere-se ao entendimento, tratandose de educação, de que qualidade e quantidade são complementares. Vários autores destacam que a preocupação com a qualidade da educação não anula a atenção contínua que se deve dar à garantia do acesso à escolarização, consubstanciado na existência de vagas em escolas em quantidade suficiente para atender toda a demanda. Nesse sentido, vale ressaltar que, como a educação tem sido proposta na maior parte das 
sociedades contemporâneas como um direito universal, qualidade do ensino apenas para poucas pessoas configura privilégio e, portanto, ausência de qualidade do ponto de vista social.

Compreender qualidade e quantidade como aspectos articulados permite identificar por que, na história brasileira, como na de outros países, a discussão aparece fortemente associada aos totais de matrícula. Mas não custa lembrar um fato já amplamente evidenciado em diversas pesquisas: "estender a escolarização não é, por si só, uma garantia de justiça escolar. Na verdade, tudo depende da maneira como a escola se organiza e do que se faz nela" (Dubet, Duru-Bellat; Vérétout, 2012, p. 35). A noção de qualidade da educação associada à garantia do acesso de todos a uma mesma escola - de qualidade - apresenta algumas armadilhas. Defender que todos tenham acesso a uma escola de qualidade parece intuito nobre e indiscutível em sociedades democráticas. Contudo, nesse caso, trata-se de qualidade para quem? Em que perspectiva? Coadunando-se com qual projeto de sociedade? Como ressalta Esteban (2008, p. 6-7),

qualidade é uma palavra polissêmica, plástica, que encerra virtualidades e positividades, expressa convergência de preocupações, permitindo a rápida construção de um consenso por criar a ideia de agregação em torno de compromissos comuns. Estas características ocultam o quanto suas diferentes acepções guardam possibilidades opostas e contraditórias de organização da escola como projeto social.

Ao se obliterar a polissemia do termo, fica assumido como universal e atemporal o sentido constituído em contextos determinados. Procede-se, assim, à "manutenção do histórico processo de colonialidade do poder em que são urdidas as relações de subalternização" (Esteban, 2008, p. 7). A propósito dos discursos que se referem aos direitos de "todas as crianças", Popkewitz (2011) observa que dão ensejo a práticas de identificação daquelas que não partilham as características de "todas as crianças", ou seja, daquelas que precisariam ser resgatadas e salvas de seus contextos de origem porque tidos como inadequados. Quando se estabelece um padrão 
único de qualidade, tem-se a produção de invisibilidade e subalternidade dos sujeitos que não se enquadram no padrão (Esteban, 2008).

Assim, o aspecto talvez mais crucial para a discussão sobre a polissemia seja a noção de que qualidade se atrela à concepção de educação considerada. Ou seja, diferentes paradigmas educacionais - ou, se se preferir, projetos educativos - vão engendrar critérios de qualidade distintos e diferentes percepções sobre o que seja uma educação de qualidade. Se é fato que haveria muitas concepções de educação passíveis de descrição, ocorre que duas são as mais recorrentes nos debates em torno do tema. De um lado, há a compreensão da função da escola para a formação humana, de outro, figuram argumentos que advogam a função da escola para o desenvolvimento econômico. No primeiro caso, a escola estaria associada à construção de uma sociedade democrática. Virginio (2012, p. 179) destaca a dificuldade de garantir a plena realização dessa função em face de critérios avaliativos padronizados:

as políticas públicas e os esforços que vêm sendo empreendidos, no sentido de garantir o sucesso escolar, podem assegurar um melhor rendimento no que tange às expectativas de êxito em relação a determinadas prescrições curriculares. Todavia, são insuficientes para dar conta da necessidade de uma educação consoante a uma sociedade democrática. Trata-se de pensar para além do critério do mérito, ou mesmo do caráter instrumental do conhecimento.

Por outro lado, a função da escola, no contexto da globalização e em face de políticas neoliberais, fortalece o foco na preparação de indivíduos com domínio de conhecimentos aplicáveis e em conformidade com demandas de cunho econômico (Stromquist, 2012). Assim, a padronização dos conteúdos escolares e processos avaliativos é defendida como decisiva para a garantia da qualidade do ensino. Nesse sentido, é preciso lembrar que, nas últimas décadas, a discussão sobre qualidade tem comparecido com especial destaque nos meios empresariais e isso não deixa de ter decorrências na área da educação. Segundo Oliveira e Araújo (2005, p. 7),

essa distinção é importante na medida em que chama a atenção para o fato de o conceito de qualidade, mesmo no mundo dos negócios, carregar significados 
e procedimentos distintos. Também não se deve perder de vista que parte significativa do debate sobre qualidade na educação é importada do mundo dos negócios e, ainda assim, nesse âmbito restrito, embute sentidos distintos.

Segundo esses autores, em algumas circunstâncias, a qualidade da educação tem se referido ao "produto final", o aluno que aprendeu, ou, pode ser também um indicativo de um processo de baixo custo, sobretudo baixo custo para o Estado.

Se falta concordância sobre o que seja qualidade da educação, como seria possível quantificá-la? A resposta a essa questão é política, mas passa também por aspectos técnicos. É uma questão política porque depende do grupo social que mais força tem para impor seu modo de ver. As elites têm maior poder para reificar a qualidade, conforme suas concepções de escola e sociedade (Bourdieu, 2014). Feita "coisa", a qualidade pode ser quantificada, deixando de fora da contagem, inevitavelmente, um amplo conjunto de aspectos cuja importância no processo educativo é inegável (como o desenvolvimento da empatia e a aprendizagem do respeito ao próximo, o estabelecimento de vínculos entre diferentes gerações, a construção da autoestima, a capacidade criativa, entre outros). Ora, esse é um efeito incontornável da quantificação. Como argumenta Afonso (2009, p. 13), "nem tudo o que conta em educação é mensurável ou comparável". Isso se torna problema quando se perde de vista que a representação estatística de um fenômeno é apenas uma maneira de ver, atendendo a critérios dos espaços de poder; pode até ser muito útil em determinadas circunstâncias, mas não corresponde à totalidade daquilo que se contabiliza. Desse modo, as estatísticas não podem ser elemento basilar para aferir o que tem importância - como se apenas tivesse importância aquilo que está expresso em números.

A resposta para a possibilidade de quantificação da qualidade é também técnica, porque implica excluir tudo aquilo que, mesmo se consensualmente considerado relevante, não pode ser expresso em números: por exemplo, como aferir com objetividade a satisfação dos alunos em aprender um novo saber? Como conhecer o desenvolvimento dos estudantes quanto 
à autoestima, às habilidades sociais e à criatividade? Ou como medir a importância do vínculo entre gerações estabelecido ao longo do processo educativo? O risco é de, por não poderem ser expressos em índices objetivos, deixar-se de dar atenção e destinar tempo a tais aspectos que são essenciais nos processos de formação da juventude. Isso evidencia que a escolha das categorias nos levantamentos estatísticos, supostamente uma questão meramente técnica, tem afinal uma indelével dimensão política. Como afirma o Rose (1991, p. 674),

paradoxalmente, no mesmo processo em que os números atingem um status privilegiado nas decisões políticas, prometem simultaneamente uma "despolitização" da política, redesenhando as fronteiras entre política e objetividade, pretendendo atuar como mecanismos técnicos automáticos para fazer julgamentos, priorizar problemas e alocar os escassos recursos.

A inexistência de consenso e toda a complexidade que envolve a definição do que seja "qualidade da educação" não impediram, no entanto, que a quantificação fosse feita desde há bastante tempo. Operando tacitamente com essa multiplicidade de questões, foram-se sobrepondo concepções e ações de quantificação da qualidade da educação ao longo do tempo. No caso brasileiro, como veremos a seguir, a mensuração remonta aos anos 1930 e foi sendo aperfeiçoada em meio ao debate sobre o que e como quantificar na qualidade. Uma breve incursão histórica permite examinar os argumentos e notar a origem das "camadas" de sentido que existem na discussão atualmente.

\section{Qualidade do alunado ou qualidade do ensino?}

A reprovação escolar não foi sempre um problema da escola brasileira (Gil, 2018). Embora desde a instalação dos primeiros colégios, ainda no período colonial, houvesse exames escolares em que os estudantes poderiam reprovar - prática que se manteve nas aulas públicas do período imperial -, tal ocorrência não aparece mencionada na documentação de ambos os períodos como frequente ou como problema. A apreensão da reprovação escolar como problema decorre basicamente da associação de 
dois aspectos: de um lado, a adesão progressiva da sociedade brasileira à noção de democratização da escolarização como direito e, de outro, a produção, desde os anos 1930, de estatísticas de educação mais confiáveis, abrangentes e regulares.

Porém, antes mesmo que esse fenômeno escolar ganhasse destaque e pudesse ser aferido estatisticamente, a quantificação dos desempenhos dos alunos deu seus primeiros passos no Brasil. A exemplo da França, foram organizadas iniciativas de aplicação de testes psicológicos aos estudantes com o intuito de identificar suas capacidades e classificá-los por níveis de inteligência. Importa notar que o desenvolvimento de tais medições, na França, deu-se a pedido do Ministério da Educação que pretendia solucionar o problema dos alunos atrasados nas aprendizagens escolares, selecionando-os para que fossem ensinados em classes especiais, adaptadas às suas necessidades. A dificuldade em assegurar o princípio democrático do direito à educação para todos, resultou na demanda feita pelo governo francês à Alfred Binet, em 1904, para "desenvolver técnicas para identificar crianças cujo fracasso escolar sugerisse a necessidade de alguma forma de educação especial" (Gould, 2003, p. 152).

Os testes de inteligência desenvolvidos por Binet permitiram a criação de escalas para medição do QI (quociente de inteligência) e essas escalas viajaram o mundo, sendo adaptadas a diferentes contextos nacionais. ${ }^{10}$ No Brasil, tais testes foram assumidos com otimismo pelos educadores à frente do projeto de democratização da escola, nas décadas de 1920 e 1930, que tinham plena convicção nos princípios meritocráticos e viam na escola uma instituição capaz de realizar a seleção justa dos talentos inatos. ${ }^{11}$ As estatísticas, nesse sentido, cumpriam o papel de medir a distância de cada indivíduo com relação à norma padrão. Criou-se, assim, um espectro da anormalidade (Lima, 2018) que, a partir dos desempenhos em testes psicológicos, servia à classificação dos alunos e engendrava processos de subjetivação. Como destaca Rose (1999), as estatísticas integram as

\footnotetext{
${ }_{10}$ Para o aprofundamento acerca das concepções e críticas acerca dos testes de QI, ver Gould (2003).

11 Importa observar que a compreensão dos talentos inatos como recurso justo para a seleção e classificação dos estudantes vai ter longa vida nos debates educacionais. Para uma crítica da ideologia das aptidões naturais, ver Bisseret (1974).
} 
"tecnologias do eu" colaborando no estabelecimento de maneiras de autogoverno, consideradas adequadas em determinado momento histórico. Rose (1999) destaca, ainda, que as estatísticas também são formas de produzir conhecimento sobre os alunos visando sustentar ações de governo sobre populações específicas, ao propor estratégias de reforma e prevenção das condutas consideradas indesejáveis no exercício do micropoder.

Os educadores brasileiros que ocuparam posições destacadas nos órgãos de condução das políticas educacionais, no período, demonstravam forte adesão ao ideário liberal. Nas primeiras décadas do século XX, defenderam vigorosamente a escola democrática, compreendendo por essa expressão uma escola em que absolutamente todas as crianças tivessem garantia de matrícula, fossem meninos ou meninas, pobres ou ricos. Garantida a matrícula a todos, a escola selecionaria, por seus próprios processos, os melhores de cada geração. A esses seria provida uma longa escolaridade, de modo a não desperdiçar os talentos. Aos demais, estariam previstos percursos de preparação para o trabalho, conduzindo cada pessoa à posição condizente às suas capacidades, de modo que cada um daria o melhor de si para o progresso da nação. Como exemplo, observe-se o que afirma Teixeira de Freitas, um dos fundadores do IBGE e que, por muitos anos, esteve à frente das estatísticas produzidas pelo Ministério da Educação e Saúde: "para ser justa, a educação deve ser extensiva a todos os cidadãos, sem privilégio algum, a não ser dos dons naturais de receptividade pessoal" (Freitas, 1945, p. 348). Jardim (1946, p. 460, destaque acrescido), do Serviço de Estatística de Educação e Saúde do Ministério da Educação e Saúde, em consonância com seus contemporâneos, considerava os testes um recurso fundamental para organização da educação:

na classificação inicial para os agrupamentos de classe e aplicação dos programas de ensino etc., e nas avaliações periódicas do processo íntimo do trabalho educacional e de seus efeitos práticos, considerando a extensão e a composição desses programas, além de outras provas objetivas são adotados os testes mentais e os testes pedagógicos ou de escolaridade, aqueles para a verificação e medida das qualidades mentais, estes para a verificação do aproveitamento dos alunos nas diversas disciplinas. 
Nesse sentido, importa observar que, nos debates dos primeiros tempos, a noção de qualidade associa-se às capacidades inatas dos alunos. Ou seja, o problema do baixo rendimento da escola brasileira, expresso em altos índices de reprovação e evasão escolar, seria, ao menos em parte, decorrência da falta de qualidade das crianças que chegavam aos bancos escolares. Havia uma evidente naturalização do baixo rendimento escolar no Brasil, algumas vezes inclusive expresso como inevitável. Serve de exemplo a afirmação de Cardoso (1949, p. 74, destaque da autora):

o aluno novo surge como uma incógnita; oferece, sempre, campo ao desenvolvimento de esperanças: talvez seja forte de trabalho, elemento que se ajuste bem ao grupo, interessado nas atividades escolares, compensando os esforços dispendidos. O repetente é um fracassado - já se revelou, dele nada se espera. Valerá, realmente, a pena mantê-lo na escola, preenchendo uma vaga e impedindo, com sua presença, a admissão de outro aluno?

Mas há também, no período, um debate específico sobre os instrumentos de aferição. Os critérios considerados pelos professores durante os exames diferiam de uma escola à outra. Assim, por exemplo, para explicar o índice de aprovação de 1935, um pouco mais favorável em algumas instituições de ensino, Almeida Junior, que ocupava o cargo de gestor do sistema de ensino estadual paulista, mencionava a variação de exigência nos exames como explicação para diferenças:

as reprovações são dados numéricos exatos; mas os critérios que as determinam, bem o sabemos, mudam de escola para escola. Os 60\% promovidos na escola A equivalerão, em nível de instrução, aos $60 \%$ da escola B? Talvez sim; talvez não. Quem examina é a autoridade escolar - o inspetor ou o diretor - e como há autoridades "baixistas", que se contentam com pouco, também as há "altistas", dispostos a apertar o crivo das aprovações (São Paulo, 1936, p. 3).

Há, ainda, menção ao reconhecimento de que, como a aprovação escolar baseava-se no resultado dos exames, era possível que os professores se pusessem a treinar os alunos especificamente para as provas, como forma de melhorar os índices. Almeida Junior afirmava que "o fato de focalizarmos a atenção sobre o fenômeno das reprovações não significa 
que a única coisa que estamos a pedir às escolas é preparar os alunos para exames" (São Paulo, 1936, p. 3).

Ao longo do período, a análise dos debates sobre a educação brasileira permite ver a emergência de uma discussão que desloca a causa da reprovação: de evidência da baixa capacidade do alunado passa a ser possível também a indicação da incapacidade de a escola cumprir seu papel social. Passemos então a esse debate.

Já desde os anos 1930, Teixeira de Freitas indicava que a preocupação exclusiva com a expansão da escola, verificada pelo aumento das matrículas, era insuficiente. Segundo ele, o principal problema da escola brasileira dizia respeito à sua pouca eficiência, uma vez que a escola tinha dificuldade de atrair a população em idade escolar, bem como manter a frequência e garantir aprovação dos alunos de uma série à outra. Ele era contra a expansão acrítica de uma escola que, na sua avaliação, precisava melhorar. Por isso considerava que

[...] o slogan que melhor exprimisse as reivindicações da infância brasileira em matéria de ensino primário teria que ser, a nosso ver, este: "antes de mais escolas, melhor Escola". Entendida como tal, uma Escola convidativa, que retenha, proteja, ensine e eduque verdadeiramente os infantes que lhe são confiados (Freitas, 1946, p. 43).

Também Anísio Teixeira (1935, p. 74), que foi Diretor da Instrução Pública no Distrito Federal, ressaltava que a escola deixava de cumprir sua função social ao reprovar e repelir parte expressiva do alunado:

não basta haver escolas para os mais capazes, é indispensável que haja escolas para todos. Não basta haver escolas para todos, é indispensável que todos aprendam.

Não é difícil avaliar quanto a modificação veio influir no conceito de rendimento da escola. Antes, dado o caráter seletivo, a reprovação era quase o índice da qualidade do ensino. Se muitos falhassem, queria isto dizer que os critérios de julgamento eram realmente eficientes e se estava depurando, para a formação das elites intelectuais e profissionais, a fina flor da população.

Se, porém, a escola tem o dever de ensinar a todos, porque todos precisam dos elementos fundamentais da cultura para viver na sociedade moderna, 
o problema se inverte. Aluno reprovado significa não já êxito do aparelho selecionador, mas fracasso da instituição de preparo fundamental dos cidadãos, homens e mulheres, para a vida comum.

Mas esse debate só vai ecoar na área de educação a partir dos anos 1950, quando a crítica aos altos índices de reprovação escolar se amplia, ora associada às explicações para o fracasso escolar que culpabilizavam os alunos e suas famílias (Patto, 1993), ora em torno da discussão sobre uma solução para o problema. Nesse sentido, é interessante observar que a Revista Brasileira de Estudos Pedagógicos, periódico oficial do Instituto Nacional de Estudos e Pesquisas Educacionais Anísio Teixeira (INEP), vai servir de espaço para a apreciação sobre as vantagens e os riscos de que se instituísse no Brasil a promoção automática (Fernandes, 2000). Os argumentos a favor apontavam para o reconhecimento de que a educação como direito de todos não poderia se ancorar em práticas pedagógicas seletivas. Luiz Alves de Matos, por exemplo, em artigo publicado em 1956, apontava "que a escola fundamental é de direito e que não deve se tornar 'uma agência selecionadora de talentos privilegiados, mas deve ser difusora da educação e da cultura a serviço da juventude e da democracia'" (Fernandes, 2000, p. 82). Os argumentos contrários não divergiam do princípio da escola democrática, mas alertavam para os riscos de uma ação precipitada que poderia ser inadequada ao contexto brasileiro. Nesse sentido, Luiz Pereira, em artigo de 1958, citado por Fernandes (2000, p. 84), denunciava

que a repetência é consequência de uma série de graves problemas e que a promoção automática, embora "eliminasse as altas porcentagens de repetência, não afetaria de modo direto e profundo os fatores desse fenômeno e que levaria à perda de um valioso termômetro do funcionamento do sistema escolar primário - os índices de repetência".

Tais debates deram ensejo a políticas que adotavam formas alternativas de avaliação e fluxo dos alunos visando reduzir a exclusão escolar (Mainardes, 1998). A partir da década de 1960, atingindo o ápice nos anos 1990, destacase a discussão sobre os problemas de fluxo escolar, com ênfase na denúncia 
da marginalização e exclusão dos mais pobres. Algumas importantes redes públicas de ensino passaram a adotar ciclos ou progressão continuada na organização de suas escolas, abandonando a progressão seriada anual que previa a possibilidade de reprovação ao final do ano, caso o aluno não atingisse pontuação suficiente nas avaliações realizadas por cada professor. A eliminação da reprovação suscitou, contudo, questionamentos sobre se não seria apenas uma forma de "resolver formalmente o fracasso escolar (índices de reprovação), mas não o problema real - o da aprendizagem dos alunos [...]" (Mainardes, 1998, p. 25). Ou seja, essas políticas resultaram em expressiva redução dos índices de reprovação nas redes em que foram implementadas, mas sofreram várias críticas e geraram desconfiança sobre a capacidade de se manter assim a qualidade do ensino.

O final do século XX foi também o período em que houve ampla difusão de políticas neoliberais. Importava, nesse sentido, atingir eficiência máxima com o mínimo de investimento público. Embora os Estados ainda almejem que a escola garanta algum nível de coesão social, nesse novo contexto, tendem a reduzir sua participação na oferta de educação pública (Stromquist, 2012). Alternativamente, passaram a concentrar atenção em processos de privatização, descentralização e accountability. Entre as estratégias de controle que caracterizam o neoliberalismo, grande importância tem sido dada às avaliações de larga escala, que pretendem medir a qualidade do ensino como forma de induzir seu incremento, por exemplo, pela competitividade suscitada entre escolas.

\section{Mensuração da qualidade: o IDEB como instrumento de medida}

A partir dos anos 1990, as orientações sobre educação produzidas por organismos internacionais acentuaram a noção de equidade como aspecto essencial (Klein, 2017). A Conferência Mundial de Educação para Todos, realizada em 1990 em Jomtien (Tailândia), reiterou a educação como direito fundamental de todos e a Declaração Mundial sobre Educação para Todos: 
satisfação das necessidades básicas de aprendizagem, assinada pelos países participantes, estabeleceu que "a educação básica deve ser proporcionada a todas as crianças, jovens e adultos. Para tanto é necessário universalizá-la e melhorar a qualidade, bem como tomar medidas efetivas para reduzir desigualdades" (Unesco, 1990, p. 4). A intenção de garantia de um "padrão mínimo de qualidade da aprendizagem" atrelou-se à recomendação de se "implementar sistemas de avaliação de desempenho" (Unesco, 1990, p. 4).

O Brasil acompanhou essa movimentação e, desde aquele período, passou a construir instrumentos de medição da qualidade do ensino que pretendiam aferir o que os alunos aprenderam na escola. Em 1991, o Ministério da Educação instituiu o Sistema de Avaliação da Educação Básica (SAEB) cujo objetivo era aferir a qualidade do ensino por avaliação amostral, realizada a cada dois anos, do desempenho de estudantes em provas padronizadas (Bonamino; Sousa, 2012). Em 1998, foi criado o Exame Nacional do Ensino Médio (ENEM) e, em 2005, agregou-se ao sistema a Prova Brasil, instituindo-se formas de avaliação não amostrais que permitissem individualizar os resultados por escola. Mais do que prover parâmetros de aferição do ensino realizado, tais políticas visam direcionar os conteúdos curriculares e o trabalho pedagógico. Bonamino e Zákia Sousa (2012, p. 380, destaques das autoras) analisam que

a estratégia da mídia de divulgação, por meio de rankings, embora não oficial, juntamente com a distribuição nas escolas da matriz de conteúdos e habilidades utilizada na elaboração dos testes de língua portuguesa e matemática, introduz perspectivas concretas de interferência mais direta no que as escolas fazem e em como o fazem.

No entanto, como, no caso brasileiro, a garantia de acesso à escola básica foi tardia e como a permanência não está assegurada, as preocupações com a aferição da aprendizagem não puderam se desarticular das medições de reprovação e abandono escolar, ${ }^{12}$ fenômenos ainda muito recorrentes

\footnotetext{
${ }^{12} \mathrm{O}$ INEP conceitua abandono escolar como a situação do aluno que deixou de frequentar a escola antes da conclusão do ano letivo, sem que haja formalização de pedido de transferência. Disponível em http://download.inep.gov.br/educacao_basica/censo_escolar/ nota_tecnica/2015/nota_tecnica_indicadores_de_rendimento_2012.pdf.
} 
no país. Em 2007, portanto, o INEP criou um índice que associava ambos os aspectos. Como afirma Fernandes (2007, p. 7),

um sistema educacional que reprova sistematicamente seus estudantes, fazendo que grande parte deles abandone a escola antes de completar a educação básica, não é desejável, mesmo que aqueles que concluam essa etapa atinjam elevadas pontuações nos exames padronizados. Por seu lado, um sistema em que os alunos concluem o ensino médio no período correto não é de interesse caso eles aprendam muito pouco. Em suma, um sistema ideal seria aquele no qual todas as crianças e adolescentes tivessem acesso à escola, não desperdiçassem tempo com repetências, não abandonassem os estudos precocemente e, ao final de tudo, aprendessem.

Tendo isso em vista, propunha-se, naquele momento, o Índice de Desenvolvimento da Educação Básica (IDEB), cuja fórmula associa informações sobre o desempenho dos estudantes em exames padronizados de Língua Portuguesa e Matemática e sobre o rendimento, pelas taxas de aprovação. No que se refere ao desempenho, os dados provêm da Prova Brasil aplicada a cada dois anos para estudantes matriculados no 5ㅇ e 9o ano do Ensino Fundamental e no 3o ano do Ensino Médio. No que se refere ao rendimento, a aprovação permite aferir problemas no fluxo escolar, já que o cálculo é feito pela diferença entre os matriculados no início do ano e os aprovados, permitindo conhecer assim os quantitativos de reprovação e abandono. Desse modo, uma escola cujos alunos apresentam boa proficiência na Prova Brasil, tem seu IDEB penalizado caso apresente altos índices de reprovação e abandono. Isso evidencia, na conformação do instrumento, a preocupação com o atendimento do preceito legal da educação como direito de todos. É condizente, ainda, com o que os Planos Nacionais de Educação (2001-2010 e 2014-2024) vêm propondo ao assinalarem, entre as metas, a demanda de regularização do fluxo escolar, pretendendo tornar progressivamente a reprovação e o abandono eventos raros. Em 2014, o PNE passou a incluir metas quantitativas, no entanto, sem explicitar a base a partir da qual foram estabelecidas as médias que se pretende atingir. Descoladas da aferição das condições objetivas para que se atinjam as metas indicadas, os números tornam-se aleatórios e expressam desejos desvinculados da realidade. 
Quadro - Plano Nacional de Educação 2014-2024 - médias projetadas

Meta 7: Fomentar a qualidade da educação básica em todas as etapas e modalidades, com melhoria do fluxo escolar e da aprendizagem de modo a atingir as seguintes médias nacionais para o ldeb

\begin{tabular}{|l|l|l|l|l|}
\hline IDEB & 2015 & 2017 & 2019 & 2021 \\
\hline Anos iniciais do Ensino Fundamental & 5,2 & 5,5 & 5,7 & $6,0^{13}$ \\
\hline Anos finais do Ensino Fundamental & 4,7 & 5,0 & 5,2 & 5,5 \\
\hline Ensino Médio & 4,3 & 4,7 & 5,0 & 5,2 \\
\hline
\end{tabular}

Fonte: PNE 2014-2024

A Meta 7 do Plano Nacional de Educação explicita que se pretende estabelecer, para o Brasil, metas tangíveis em termos de qualidade da educação e viabilizar a responsabilização, para o quê, a quantificação é considerada fundamental.

O IDEB foi proposto como forma de estabelecer um padrão de qualidade na educação do país. Trata-se de um índice destinado a monitorar os resultados por escola, visando fornecer elementos aos gestores das redes de ensino, informações supostamente acessíveis às famílias acerca das instituições em que seus filhos estão matriculados, como também elementos para avaliação da educação brasileira como um todo. Assim, pretende-se que o índice sirva para balizar políticas educacionais como também para o controle social sobre a qualidade do ensino. A literatura especializada tem, contudo, apontado alguns de seus riscos e limites, muitos dos quais decorrem dos usos inadequados que se faz dos números. Um aspecto central, nesse sentido, é que os índices educacionais fomentam a ilusão de que seja possível conhecer com objetividade a qualidade das instituições de ensino. Questiona-se a

utilização dos resultados das avaliações em larga escala e dos índices por elas criados como única fonte para a análise do trabalho desenvolvido pelas escolas, considerando que os desempenhos médios obtidos não podem ser

\footnotetext{
${ }^{13}$ Embora o IDEB tenha uma escala de 0 a 10, ela não se comporta como na tradicional avaliação escolar. Em função do modo como é feito o cálculo, 6,0 corresponde a um alto IDEB e a diferença entre 4,0 e 6,0 é maior do que pode parecer. Notas abaixo de 2,0 e acima de 8,0 são extremamente raras. Para maiores informações sobre aspectos técnicos, ver Soares e Xavier (2013).
} 
traduzidos como retrato fiel da qualidade das instituições (Almeida; Dalben; Freitas, 2013, p. 1155).

Além disso, tem sido unânime a crítica ao fato de que o índice desconsidera o nível socioeconômico dos estudantes, levando a crer que as escolas com alto IDEB teriam um ensino melhor do que as demais, quando se sabe que a correlação entre desempenho dos estudantes e nível socioeconômico é sempre alta.

Assim, ao atribuir a esse indicador o status de síntese da qualidade da educação, assume-se que a escola pode superar toda a exclusão promovida pela sociedade. Há uma farta literatura que mostra que isso é impossível. Todos os alunos têm direito de aprender, e os conhecimentos e habilidades especificados para educação básica devem ser os mesmos para todos. No entanto, obter este aprendizado em escolas que atendem alunos que trazem menos de suas famílias é muito mais difícil, fato que deve ser considerado quando se usa o indicador de aprendizagem para comparar escolas e identificar sucessos (Soares, 2011).

Também é preciso ter presente que o IDEB não permite aferir valor agregado (ou seja, a diferença de proficiência entre o início e o final da escolarização) e, ainda, que os exames padronizados de proficiência não avaliam conteúdos importantes à formação dos estudantes, restringindo-se à leitura e matemática. Ficam de fora, por exemplo, componentes tais como Geografia, Arte e Ciências ou, ainda, competências como a valorização da diversidade de saberes, o cuidado de si mesmo, dos outros e do planeta, a colaboração com a construção de uma sociedade justa, democrática e inclusiva (Brasil, 2018, p. 9).

Em que pesem essas ponderações, amplamente conhecidas e consideradas por estatísticos e pesquisadores que se debruçam sobre o tema, a circulação dos números desprende-se dessas chaves de leitura e as cifras ganham autonomia. Os efeitos dos índices extrapolam suas proposições iniciais. ${ }^{14}$

\footnotetext{
${ }^{14}$ Cabe assinalar que há diferenças entre o que as equipes técnicas de produção de estatísticas pretendem dos números e o que intencionam os gestores ao encomendarem a criação de índices. Para estes, é frequentemente mais explícito o objetivo de indução das políticas proporcionado pela divulgação das estatísticas que, na fala daqueles, aparece mais como distorção ou abuso no uso dos números. Esse aspecto não foi aqui sistematicamente verificado, mas se configura em importante questão que merece estudos mais acurados.
} 
Assim, por exemplo, a recepção do índice pelas escolas pode resultar em ações cujo único objetivo é a melhoria do índice e não necessariamente a melhoria da qualidade do trabalho pedagógico. Soares e Xavier (2013, p. 915), assinalam que

o uso de um indicador como medida única da qualidade da escola e dos sistemas fará, naturalmente, com que as escolas busquem maximizá-lo e, como isso pode ser feito de maneiras pouco adequadas pedagogicamente, pode levar a um sistema educacional disfuncional.

É preciso, portanto, considerar os efeitos de subjetivação que o IDEB provoca no espaço escolar (Klein, 2017). Estabelecer um conjunto de aspectos a partir dos quais se infere a qualidade, mesmo que seja recurso metodologicamente pertinente, esbarra no fato de que a recepção do índice acaba por circunscrever os esforços apenas no que se refere a esse conjunto restrito. Ou seja, se a proficiência verificada se limita à leitura e à matemática, não é, necessariamente, porque os formuladores do índice consideram que seja apenas essa a tarefa da escola, mas porque esse seria um parâmetro suficiente para um cálculo padronizado. No entanto, os sujeitos da escola, os gestores de redes de ensino e a grande imprensa tendem a receber essa restrição metodológica como prescrição pedagógica acerca dos conteúdos curriculares com os quais devem se ocupar. Tais efeitos fogem ao controle dos estatísticos, fazendo com que o instrumento de medição atue na construção daquilo que supostamente ele deveria apenas medir. Menos que uma distorção de funcionamento, essa é uma das características dos processos de quantificação.

\section{Considerações finais}

Assumir as estatísticas de educação como objeto de análise, buscando escrutinar o modo como são construídas e interpretadas, corresponde aqui a considerá-las como partícipes nos processos educacionais - e não meros instrumentos de medição. No que se refere à quantificação da qualidade, a dificuldade tem início já na definição do que seja uma educação de 
qualidade. Longe de ser questão simples e consensual, o que busquei sublinhar foi o fato de que tais concepções são resultado de processos sociohistóricos que, em meio a constantes disputas, engendram a coexistência de sentidos nem sempre concordantes. Tais sentidos, por sua vez, são mobilizados nos debates atuais, com peso e eficácia variados.

O segundo elemento que pretendi destacar neste artigo foi a compreensão, decorrente da análise de fontes históricas, de que, frequentemente, o que se considera como aferição da qualidade do ensino é o exame das capacidades do alunado. Aqui cabe explicitar uma questão sociológica importante, tratada por Bourdieu em vários trabalhos seus. A análise dos processos de quantificação da reprovação escolar tem contribuído para

descrever os mecanismos objetivos que determinam a eliminação contínua das crianças desfavorecidas. Parece, com efeito, que a explicação sociológica pode esclarecer completamente as diferenças de êxito que se atribuem, mais frequentemente, às diferenças de dons. [...] A herança cultural, que difere [...] segundo as classes sociais, é responsável pela diferença inicial das crianças diante da experiência escolar e, consequentemente, pelas taxas de êxito (Bourdieu, 2012, p. 41-42).

A tradição de avaliação da qualidade do ensino pela medição do que sabem os alunos se mantém no IDEB. Embora esse índice busque equilibrar a verificação do desempenho dos alunos em provas padronizadas com os dados quantitativos de fluxo escolar, o foco segue circunscrito aos alunos. Não há menção às condições de infraestrutura das escolas, não há ponderação sobre a formação e remuneração dos professores e demais trabalhadores da educação, não se contabiliza o gasto público e/ou privado por aluno, ou seja, não entram no cálculo o nível socioeconômico das famílias e os recursos destinados ao ensino. Esse modo de proceder à quantificação da qualidade sugere uma equação demasiadamente simples, deixando de fora da análise parte importante da complexidade da estrutura social que perpassa e constitui a instituição escolar. 
Assim, um dos efeitos da quantificação da qualidade que pretendi enfatizar neste artigo diz respeito à excessiva simplificação da questão da qualidade em educação expressa pelas estatísticas. Se, por um lado, os números são um útil recurso de objetivação que auxilia na análise de situações complexas e na tomada de decisões políticas e educacionais, por outro, induzem a assumir que tudo o que importa estaria expresso estatisticamente. Como destaca Desrosières (2000, p. 9), é preciso compreender como os fatos sociais são transformados em estatísticas, levando em conta que "a história de sua gestação permite esboçar, retraçando as controvérsias e os debates antigos, um espaço das articulações entre as linguagens técnicas e seus usos no debate social". Do meu ponto de vista, não se trata de abandonar o recurso aos números, mas de se estar mais atento a seus riscos e limites (Gil, 2019).

Sendo a educação de qualidade um direito assegurado pela legislação brasileira, é preciso levar em conta ainda outro aspecto fundamental. Em uma sociedade entusiasta da "objetividade", contar algo é, como já mencionado, supondo descrevê-lo, fazê-lo existir. Daí um dilema: como garantir o direito à educação sem medidas, sem parâmetros, sem estatísticas? Diante disso alguns autores defendem a imprescindibilidade do estabelecimento objetivo de padrões de qualidade em educação (Oliveira; Araújo, 2005). A questão não é de pouca importância, mas seu aspecto positivo não anula os riscos já apontados. O espaço para os embates - de ideias e de políticas - encontra-se, evidentemente, em aberto. Compreender as estatísticas como elemento mobilizado nesse jogo é já uma maneira menos restrita de tomá-la em consideração.

Natalia de Lacerda Gil é Doutora em Educação e professora e pesquisadora na Faculdade de Educação da Universidade Federal do Rio Grande do Sul (UFRGS).

$\triangle$ natalia.gil@uol.com.br 


\section{Referências}

1. AFONSO, Almerindo J. Nem tudo o que conta em educação é mensurável ou comparável. Crítica à accountability baseada em testes estandardizados e rankings escolares. Revista Lusófona de Educação, n. 13, p. 13-29, 2009.

2. ALMEIDA, Luana C.; DALBEN, Adilson; FREITAS, Luiz Carlos de. O IDEB: limites e ilusões de uma política educacional. Educação \& Sociedade, v. 34, n. 135, p. 1153-1174, 2013.

3. BISSERET, Noële. A ideologia das aptidões naturais. In: DURAND, José Carlos. (org.). Educação e hegemonia de classe. Rio de Janeiro: Zahar, 1974. p. 30-67.

4. BONAMINO, Alicia; SOUSA, Sandra Z. Três gerações de avaliação da educação básica no Brasil: interfaces com o currículo da/na escola. Educação e Pesquisa, v. 38, n. 2, p. 373-388, abr.-jun. 2012.

5. BOURDIEU, Pierre. A economia das trocas lingüísticas: o que falar quer dizer. São Paulo: EDUSP, 1998.

6. BOURDIEU, Pierre. A escola conservadora: as desigualdades frente à escola e à cultura. In: NOGUEIRA, Maria Alice; CATANI, Afrânio (Orgs.). Escritos de educação. 13. ed. Petrópolis: Vozes, 2012. p. 39-64.

7. BOURDIEU, Pierre. Sobre o Estado: cursos no Collège de France (1989-92). São Paulo: Companhia das Letras, 2014.

8. BRASIL. Ministério da Educação. Base nacional comum curricular. Brasília: MEC, 2018.

9. CARDOSO, Ofélia B. O problema da repetência na escola na escola primária. Revista Brasileira de Estudos Pedagógicos, v. 13, n. 35, p. 74-88, 1949.

10. DESROSIÈRES, Alain. La politique des grands nombres : histoire de la raison statistique. Paris: La Découverte, 2000.

11. DUBET, François; DURU-BELLAT, Marie; VÉRÉTOUT, Antoine. As desigualdades escolares antes e depois da escola: organização escolar e influência dos diplomas. Sociologias, v. 14, n. 29, p. 22-70, 2012.

12. ESTEBAN, Maria Teresa. Silenciar a polissemia e invisibilizar os sujeitos: indagações ao discurso sobre a qualidade da educação. Revista Portuguesa de Educação, v. 21, n. 1, p. 5-31, 2008.

13. FERNANDES, Claudia de O. A promoção automática na década de 50: uma revisão bibliográfica na RBEP. Revista Brasileira de Estudos Pedagógicos, v. 81, n. 197, p. 76-88, 2000.

14. FERNANDES, Reynaldo. Índice de desenvolvimento da educação básica (Ideb). Brasília: Instituto Nacional de Estudos e Pesquisas Educacionais Anísio Teixeira, 2007.

15. FREITAS, Mário A.T. de. Novos objetivos para a educação no Brasil. Revista Brasileira de Estudos Pedagógicos, v. 4, n. 12, p. 346-360, 1945. 
16. FREITAS, Mário A. T. de. O ensino primário brasileiro no decênio 1932 1941. Rio de Janeiro: IBGE, 1946.

17. GIL, Natália de L. Reprovação escolar no Brasil: história da configuração de um problema político-educacional. Revista Brasileira de Educação, v. 23, p. 1-23, 2018.

18. GIL, Natália de L. Estatísticas e educação: considerações sobre a necessidade de um olhar atento. Pensar a Educação em Revista, v. 5, n. 2, p. 1-29, jun.-ago. 2019.

19. GOULD, Stephen J. A falsa medida do homem. São Paulo: Martins Fontes, 2003.

20. HACKING, lan. The taming of chance. Cambridge: Cambridge University, 1990.

21. IBGE - Instituto Brasileiro de Geografia e Estatística. Educação 2017. PNAD Contínua. Rio de Janeiro: IBGE - Diretoria de Pesquisas, Coordenação de Trabalho e Rendimento, 2018.

22. JARDIM, Germano. A coleta da estatística educacional IV. Revista Brasileira de Estudos Pedagógicos v. 7, n. 21, p. 452-463, 1946.

23. KLEIN, Delci H. IDEB e maquinarias: a produção, a quantificação e a expressão da qualidade da educação brasileira. 2017. Tese (Doutorado em Educação). Faculdade de Educação. Universidade Federal do Rio Grande do Sul, Porto Allegre, 2017.

24. LIMA, Ana Laura G. A “criança-problema" na escola brasileira. Curitiba: Appris, 2018.

25. MAINARDES, J. A promoção automática em questão: argumentos, implicações e possibilidades. Revista Brasileira de Estudos Pedagógicos, v. 79, n. 192, p. 1629, 1998.

26. MATOS, Luiz A. de. A aprovação e a reprovação escolar. Revista Brasileira de Estudos Pedagógicos, v. 26, n. 63, p. 254-257, 1956.

27. OLIVEIRA, Romualdo P. de; ARAUJO, Gilda C. de. Qualidade do ensino: uma nova dimensão da luta pelo direito à educação. Revista Brasileira de Educação, n. 28, p. 5-23, 2005.

28. PATTO, Maria Helena S. A produção do fracasso escolar. São Paulo: T.A. Queiroz, 1993.

29. PEREIRA, Luiz. A promoção automática na escola primária. Revista Brasileira de Estudos Pedagógicos, v. 30, n. 2, p. 105-107, out./dez. 1958.

30. POPKEWITZ, Thomas. PISA: numbers, standardizing conduct, and the alchemy of school subjects. In: PEREYRA, Miguel A.; KOTTHOFF, Hans-Georg; COWEN, Robert (eds.). PISA under examination: changing knowledge, changing tests, and changing schools. Rotterdam: Sense Publishers, 2011. p. 31-46. 
31. PORTER, Theodore M. Trust in numbers: The pursuit of objectivity in science and public life. Princeton: University of Princeton Press, 1995.

32. ROSE, Nikolas. Governing by numbers: figuring out democracy. Accounting Organizations and Society, v. 16, n. 7, p. 673-692, 1991.

33. ROSE, Nikolas. Powers of freedom: reframing political thought. Cambridge: Cambridge University Press, 1999.

34. SÃO PAULO. Secretaria da Educação e da Saúde Pública. Diretoria do Ensino. As reprovações na escola primária (O fenômeno das reprovações. Análise das causas. Medidas contra o mal. Dados estatísticos). Boletim n. 7, 1936.

35. SOARES, José Francisco. José Francisco Soares: IDEB na lei? Simon's Site, 13 jul. 2011. Disponível em https://www.schwartzman.org.br/sitesimon/?p=2352

36. SOARES, José Francisco; XAVIER, Flávia P. Pressupostos educacionais e estatísticos do IDEB. Educação \& Sociedade, v. 34, n. 135, p. 903-923, 2013.

37. STROMQUIST, Nelly P. Educação latino-americana em tempos globalizados. Sociologias, v. 14, n. 29, p. 72-99, jan./abr. 2012.

38. TEIXEIRA, Anísio. Educação pública: administração e desenvolvimento. Rio de Janeiro: Officina Graphica do Departamento de Educação, 1935.

39. UNESCO. Declaração Mundial sobre Educação para Todos: satisfação das necessidades básicas de aprendizagem. Jumtien: U̧NESCO, 1990.

40. VIRGINIO, Alexandre S. Educação e sociedade democrática: interpretações sociológicas e desafios à formação política do educador. Sociologias, v. 14, n. 29, p. 176-212, 2012.

Recebido: 9 dez. 2020.

Aceito: 15 mar. 2021. 